\title{
LEITURAS CRÍTICAS SOBRE A “CONDIÇÃO HUMANA": A PARTIR DOS RELATOS DA BÍBLIA E DE HESÍODO
}

Rafael Guimarães Tavares Silva*

RESUMO: Partindo de relatos acerca da condição humana, conforme as tradiço forme as tradiçôs poemas de Hesiodo), indagamo-nos sobre as formas por que humanidade - diferenciando-se da divindade - encontra na submissão animal um importante momento constitutivo. O sacrifício prometeico, por um lado, e a nomeação adâmica, por outro, apresentam ainda implicações para a especificação da humanidade nos gêneros masculino e feminino. Nossa leitura tende a apontar a relação entre carnivorismo e patriarcalismo nessas narrativas, nas quais uma divindade masculina nao apenas figura como a autoridade que impõe o sacrificio de carne, mas tambem instaura autorich que impore o sacilfio de carne, mas tamberm instaura arbitrariamente a diferenciaço entre homens e mulheres, dando a precedência (temporal e hierárquica) a uma das partes. Nosso objetivo e, mais do que apontar o modo por que se impõem essas diferenciações, indicar uma possibilidade de questionar e ultrapassar a autoridade e a arbitrariedade de tais imposições.

PALAVRAS-CHAVE: Gênesis; Hesíodo; antropogonia; carnivorismo; patriarcalismo.

\author{
gtsilva.rafa@gmail.com \\ Mestrando pelo Programa de Pós-Graduação em Estudos \\ Literários da Faculdade de Letras da UFMG.
}

ABSTRACT: Departing from narratives about the human condition, according to Hebrew and Greek traditions (in the biblical Genesis and in the Hesiodic poems), we question the ways in which humanity - differentiating itself from divinity - finds an important constitutive moment in animal submission. Anima sacrifice by Prometheus, on the one hand, and animal nomination by Adam, on the other, present further implications to the specification of humanity in genres (masculine and feminine) Our reading intends to highlight the relation between carnism and patriarchy in these narratives, where a masculine divinity (

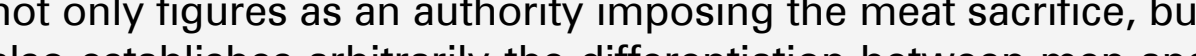
also establishes a a women, giving the precedence (temporal and hierarchical) to one of them. Our objective is, more than indicating the way in which these differentiations are imposed, to suggest a possibility of questioning and surpassing the authority and arbitrariness of such impositions.

KEYWORDS: Genesis; Hesiod; anthropogony; carnism; patriarchy. 
A humanidade com frequência refletiu sobre suas condições de existência e - na tentativa de encontrar respostas a seus delicados questionamentos - propôs inúmeras narrativas "genéticas", nas quais avançava suas hipóteses (e teses) para pensar os diferentes modos por que a existência humana teria vindo a se estabelecer em tais condições. Cosmogonias, teogonias e antropogonias são algumas das "gêneses" com que a humanidade refletiu sobre si mesma, especulando sobre o passado, o presente e o futuro. Algumas dessas narrativas "genéticas" não apenas buscaram explicar ou especular acerca de uma dada situação, mas se esforçaram por fornecer elementos que a justificassem. Desse modo, reflexão, investigação, explicação e justificativa muitas vezes se entrelaçam nessas narrativas, sendo preciso atentar para o sentido daquilo que é sugerido por elas. ${ }^{1}$

O edifício cultural do Ocidente encontra dois de seus pilares fundamentais nas tradições judaicas e helênicas, nas quais foram escritos muitos dos textos fundadores daquilo que viria a constituir sua religião, sua poesia, sua filosofia sua ciência. ${ }^{2}$ Pretendemos propor uma leitura de algumas das narrativas de eventos primordiais com que essas tradições especularam sobre a gênese da condição humana principalmente a partir da Bíblia e dos poemas de Hesíodo - a fim de nos questionarmos acerca de um estado que ainda é, em grande parte, o nosso e que essas tradições já tinham se proposto a pensar, investigar, explicar e justificar.
Embora leituras desse tipo, associando a tradição helênica a outras tradições (sobretudo orientais), tenham sido limitadas por certo etnocentrismo imperante nos séc. XIX e XX, ${ }^{3}$ nas últimas décadas o esforço de inúmeros estudiosos tem reaproximado essas tradições, demonstrando a fertilidade de uma abordagem transdisciplinar. Jacqueline Duchemin, Walter Burkert, Martin West, entre outros, indicam que o "milagre grego" não teria sido o resultado do trabalho de um "ocidente primordial" ensimesmado, mas que a possibilidade de desenvolvimento da cultura helênica se deu na medida em que os gregos eram os mais orientais dentre os povos ocidentais. ${ }^{4}$ Nosso texto insere-se nesse movimento de abertura a outras tradições e deseja oferecer novos vislumbres de relações subjacentes a certos programas a partir de uma leitura atenta às multiplicidades sugeridas por eles. Ressalvamos, contudo, aquilo que Derrida, ao aproximar certos textos dessas culturas, já prevenira:

Aproximando assim a Gênese e o mito grego, [...] não especulo sobre nenhuma hipótese de história comparada ou de análise estrutural dos mitos. Esses relatos são de estatuto e de origem heterogêneos. Não os tenho tampouco por causas ou origens do que quer que seja. Nem por verdades ou vereditos. Apenas e ao menos por duas traduções sintomais cuja necessidade interna se confirma tanto mais que certos traços se recobrem em parte de uma tradução a outra.

EM TESE BELO HORIZONTE $\quad$ v. $22 \quad$ N. 2 MAIO-AGo. 2016 SILVA. Leituras críticas sobre a "condição humana": a partir dos relatos [...] P. 103-124

Crítica Literária, outras Artes e Mídias 
Acreditamos que a necessidade interna dessas duas "traduções sintomais", apesar de suas profundas diferenças, ${ }^{6}$ efetivamente se confirme e pretendemos mostrar de que modo seus traços se recobrem nelas. Para isso, acompanharemos o desenvolvimento da humanidade a partir da divindade - em clara diferença com relação aos animais -, o surgimento de uma "condição humana" envolvendo o processo de especificação em dois gêneros (macho e fêmea) e a imposição do sofrimento, da reprodução e do trabalho (entendido como o labor de Hannah Arendt). Contudo, mais do que indicar o recobrimento desses traços nas narrativas que nos propomos a ler, desejamos apontar elementos presentes nelas que nos possibilitem ultrapassar seus limites.

Antes de começarmos a leitura dos textos, gostaríamos de fazer uma breve consideração sobre o termo "mito", já que, em sua relação com a "literatura", constitui o tema do número atual desta revista e suas implicações são importantes para nossa proposta de leitura. Paul Ricoeur tem um instigante ensaio chamado "Mito e história", no qual aborda questões relativas ao pensamento mítico, à narrativa, à temporalidade e à historicidade no interior das tradições helênica e judaica. Embora não possamos refazer o fio argumentativo proposto por ele para o desenvolvimento de diferentes concepções históricas no interior dessas duas tradições, desejamos retomar alguns pontos de seu texto para nossa própria reflexão. Segundo o autor, "com o mito, tratamos com um tipo particular de explicação que manterá uma relação complexa com a história. Esse tipo de explicação consiste essencialmente em uma função fundadora dos mitos"'. Tal noção é válida em inúmeras narrativas helênicas, sobretudo naquelas em que um valor fundacional está presente in illo tempore (como em inúmeros eventos narrados nos poemas de Hesíodo). Para a tradição hebraica, contudo, na medida em que configura uma "teologia da história" (segundo a qual haveria um sentido transcendente no próprio devir histórico), já não poderíamos mais falar de "mito" no sentido mencionado acima. Para o autor,

devemos admitir que chamando de mito a própria história da salvação, estendemos a noção de mito além do sentido estrito de uma história das origens in illo tempore. A história da salvação desenrola-se mais no tempo dos homens do que no tempo dos deuses. Essa diferença fundamental deve nos tornar mais prudentes no uso do termo mito para qualificar as interpretações teológicas como as da história da salvação. ${ }^{8}$

Ainda que seja possível falar de "mito", em sentido lato tanto para os poemas hesiódicos, quanto para os relatos bíblicos do Gênesis, no caso desse segundo grupo de narrativas já existe certa subordinação do mito à história. Ou seja, a sua qualidade de "mito" - narrativa fundadora in illo tempore - já está de certo modo comprometida. Cientes disso, comecemos nossa leitura com alguma prudência...

EM TESE

BELO HORIZONTE

v. 22

N. 2

MAIO-AGO. 2016

SILVA. Leituras críticas sobre a "condição humana": a partir dos relatos [...] P. 103-124

Crítica Literária, outras Artes e Mídias 
O Gênesis inicia-se com um primeiro relato cosmogônico, perpassado de vestígios do mito de origem babilônico, no qual apresenta, numa narrativa de sete dias, a divisão da luz e da treva, das águas acima e abaixo do céu, da terra e das águas, ${ }^{9}$ além da criação da vegetação, dos astros, dos animais e do homem. Esse "primeiro relato" procede do chamado "Documento Sacerdotal", escrito por uma fonte que se convencionou chamar $\mathrm{P}$ [Priestercodex], num momento posterior à escrita do relato sobre a criação de Adão e Eva, talvez no período do grande Exílio, ou pouco depois, no século VI AEC. ${ }^{10}$ Já está demonstrado que as motivações para essa introdução, escrita posteriormente, são sobretudo litúrgicas e ritualísticas, ${ }^{11}$ mas não deixa de ser curioso o fato de que nesse "primeiro relato" a criação da humanidade já se dê especificada nos dois gêneros - posto que "macho e fêmea criou-os" $[z k r$ unnqbe] (Gênesis 1:27). ${ }^{12}$ Esse fato curioso é um primeiro paralelo com o "mito das idades", apresentado nos Trabalhos e dias.

Tal como no Gênesis, Hesíodo oferece dois relatos diversos acerca das origens da humanidade e de sua condição. ${ }^{13} \mathrm{O}$ mais famoso deles é o que envolve Zeus, Prometeu e Pandora - sobre o qual nos deteremos na sequência de nosso argumento - e que aparece, com propósitos diferentes, tanto na Teogonia quanto nos Trabalhos e dias. O outro relato, importantíssimo para a constituição de um tópos poético e filosófico na tradição greco-latina, é o "mito das idades" (ou "mito das raças"), tratado entre os vv. 106-176 dos Trabalhos e dias. ${ }^{14}$ Baseando-nos no que afirma um tradutor brasileiro do poema, ${ }^{15}$ podemos propor o seguinte resumo dessa passagem: cada idade ou raça tem relação com um metal, segundo o qual vem a ser nomeada, numa ordem partir do metal mais valioso; ouro, prata, bronze, ferro. Intercala-se, entre as duas últimas, a raça dos heróis, que não possui equivalente metálico. Sua inserção no relato das idades completa o quadro que explica a origem divina de vários seres: daímones terrenos, daímones subterrâneos, heróis, mortos do Hades e humanos da geração atual. Tratase, por um lado, de um mito etiológico que explica a existência de várias entidades (numa divisão estrutural do mundo divino), por outro, de um mito genealógico que narra a gradual constituição da condição humana.

Os paralelos entre o "primeiro relato" bíblico e o "mito das idades" hesiódico são surpreendentes: ${ }^{16} \mathrm{em}$ ambos se trata de como a divindade é responsável pela criação da humanidade, num ato que já a divide nos gêneros masculino e feminino, ${ }^{17}$ sem que a princípio haja a necessidade de trabalhar, na medida em que a alimentação à base de frutos é espontânea e a existência se dá num estado de júbilo e felicidade. ${ }^{18} \mathrm{O}$ mito de Hesíodo, contudo, oferece uma especulação mais complexa sobre o desenvolvimento gradual da condição humana, ${ }^{19}$ enquanto o "primeiro relato" bíblico apresenta considerações de caráter didático numa forma poética com menos dramaticidade e mais limitado desenvolvimento narrativo. ${ }^{20} \mathrm{~A}$ mais fecunda comparação para o que pretendemos mostrar,
EM TESE
BELO HORIZONTE
v. 22
N. 2
MAIO-AGO. 2016
SILVA. Leituras críticas sobre a "condição humana": a partir dos relatos [...] P. 103-124

Crítica Literária, outras Artes e Mídias 
no entanto, se dará entre o "segundo relato" bíblico (com a criação de Adão e Eva por Javé Elohim, ou conforme a tradução da Torá, Eterno Deus) ${ }^{21}$ e o mito de Prometeu e Pandora, em Hesíodo, ${ }^{22}$ nos quais acreditamos encontrar paralelos importantes para indicar certos aspectos do estado ao qual aludíamos no começo de nosso texto.

O "segundo relato" (Gênesis 2:4b - 3:24) conta como o Eterno Deus formou o "homem" a partir do "pó da terra", insuflando-lhe vida, e fez brotar um jardim para que cultivasse e guardasse. Em seguida, ele formou como companhia para o "homem" todos os animais (que foram nomeados por ele) e, como companheira, fez-lhe a mulher, a partir de uma de suas costelas. Essa é a primeira parte da narrativa. ${ }^{23} \mathrm{~A}$ segunda concentra-se no drama da "queda", tal como veio a se passar sob a influência da serpente: a mulher é tentada a desobedecer à ordem do Eterno Deus, o casal infringe o interdito divino, a infração é descoberta, investigada e os castigos são instituídos: trabalho e sofrimento para a existência humana (ainda que a esperança de vida só subsista no próprio trabalho e nas dores do parto). Contudo, a verdadeira conclusão do relato inteiro só se dá com a expulsão do Éden, marcando o fim da proximidade na separação que caracterizava a condição da criatura. ${ }^{24}$

O mito de Prometeu e Pandora apresenta vários traços que coincidem com o que está presente no relato bíblico e, embora seu tratamento esteja um pouco disperso tanto na Teogonia, quanto nos Trabalhos e dias, é possível notá-lo com um breve resumo de seus fatos principais. ${ }^{25}$ Segundo Hesíodo, quando deuses e homens estavam certa vez reunidos em Mecona, ${ }^{26}$ Prometeu ofertou a Zeus um grande boi, procedendo à divisão de suas partes e à instituição do primeiro sacrifício (Teogonia, vv. 535-7). O titã, porém, tentou enganar o soberano do Olimpo, oferecendo a parcela que continha ossos como se fosse a melhor e aquela que continha as carnes comestíveis como se fosse a pior (Teogonia, vv. 538-55; Trabalhos e dias.v. 48) ${ }^{27}$ Como punição pelo desafio [éris] e pelo engano [exapátē], Zeus tomou o sustento [bíos] e o fogo [pûr] dos homens, embora Prometeu tenha recuperado o elemento ígneo pouco depois (Teogonia, vv. 558-69; Trabalhos e dias, vv. 503). Como punição por esse comportamento recidivo, Zeus plasmou um mal terrível - dotando-o com aparência de um bem - e ofereceu-o como dádiva à humanidade: assim teria surgido a primeira mulher (Teogonia, vv. 570-616; Trabalhos e dias, vv. 54-105). ${ }^{28}$ Ela foi chamada Pandora - por ter recebido presentes [dôra] de todos os deuses ${ }^{29}$-, mas, além de ser um mal em si mesma, foi a responsável por trazer inúmeros outros males à humanidade, quando abriu o pithos [jarro] que devia ser mantido lacrado: em todo caso, ela o fechou a tempo de impedir que a própria Esperança [Elpís] se perdesse. ${ }^{30}$

Os temas comuns a esses relatos podem ser elencados de modo geral sob as seguintes ideias: origem divina da

EM TESE BELO HORIZONTE $\quad$ v. $22 \quad$ N. 2 MAIO-AGo. 2016 SILVA. Leituras críticas sobre a "condição humana": a partir dos relatos [...] P. 103-124

Crítica Literária, outras Artes e Mídias 
humanidade; ${ }^{31}$ subordinação dos animais ao ser humano; surgimento da mulher como um bem aparente (embora se revele um mal);32 infração de um interdito divino; sua punição com a condenação a uma existência vinculada ao trabalho e ao sofrimento; manutenção de alguma esperança para a subsistência e a supervivência da humanidade. Essas coincidências são evidentes mesmo a uma leitura rasteira das duas narrativas e muitos comentadores já as mencionaram em estudos anteriores. ${ }^{33}$ Nosso objetivo, contudo, mais do que evidenciar esses traços comuns, é esclarecer a relação sugerida por eles e apontar um modo de lê-los que nos permita ultrapassar seus limites.

Se fizermos o caminho inverso daquele que a estrutura dessas narrativas nos sugere, ou seja, se partirmos da punição imposta à humanidade e recuarmos pelo desenvolvimento gradual de sua condição até os primeiros momentos de divisão entre animal, humano e divino, poderemos nos questionar acerca dos fundamentos sobre os quais se baseiam certas relações implicitamente sugeridas nesse entremeio. A condição penosa da humanidade - na qual trabalho e sustento da casa cabem ao homem, enquanto a procriação dos filhos cabe à mulher - é configurada como uma punição que remonta à própria humanidade. ${ }^{34}$ Essa punição reforça uma divisão anteriormente instituída pela divindade, instalada no cerne daquilo que parece constituir o ser humano, qual seja, a divisão sexual em dois gêneros: a mulher revela-se diferente do homem não apenas por ser derivada (constituída depois e a partir dele), mas também porque suas funções não coincidem em nenhum ponto. Ainda assim, enquanto espécie humana, ambos estão acima de todos os animais, na medida em que o poder da própria divindade parece fundamentar sua prevalência sobre as demais criaturas. ${ }^{35}$ Como se vê, em cada uma dessas instâncias, a autoridade que baseia as diversas imposições de um elemento sobre outro é a divindade, ou seja, tal autoridade advém do próprio autor da criação. Contudo, qual é o fundamento dessa autoridade?

O poder.$^{36} \mathrm{O}$ poder criador e divino fundamenta sua autoridade sobre tudo aquilo que se encontra aquém dele, ou seja, sobre tudo aquilo que veio a ser por meio de sua vontade. Partindo da constatação desse poder, as narrativas do Gênesis e dos poemas de Hesíodo indagam-se sobre o modo por que esse poder veio a determinar a condição humana e encontram nesse mesmo poder a justificativa para a manutenção dessa condição humana sempre que tais narrativas são retomadas. Essa manutenção, contudo, exige que o fundamento do poder divino se mantenha inquestionável para os ouvintes dessas novas performances, ou seja, exige que esse poder continue a ser apenas constatado pelo público dessas narrativas. Se esse fundamento fosse questionado e, mais do que isso, abalado pela descoberta de uma fenda em seu arranjo - de um buraco em sua contextura -, é de se supor que toda a cadeia de imposições implicadas pelo poder da divindade seria colocada em risco.

EM TESE BELO HORIZONTE $\quad$ v. $22 \quad$ N. 2 MAIO-AGo. 2016 SILVA. Leituras críticas sobre a "condição humana": a partir dos relatos [...] P. 103-124

Crítica Literária, outras Artes e Mídias 
Aqui podemos questionar: no momento histórico da recepção dessas narrativas sobre eventos antiquíssimos e primordiais, o que fundamenta ainda o poder da divindade subjacente a elas? Num nível imediato, é possível que as próprias narrativas fundamentem tal poder. Contudo, o poder dessas narrativas é inevitavelmente carente de lastro. Como nenhuma narrativa primordial pode se autorizar com um testemunho histórico, uma vez que tal narrativa instaura a própria possibilidade da história, sua fundamentação encontra-se encerrada em si mesma, ou antes, na fé com que essa narrativa é recebida. ${ }^{37}$ Ainda aqui podemos questionar: de que modo essa fé na narrativa (e, em última instância, na própria divindade) se exprime e se concretiza? De que forma ela se torna possível? Para o contexto de performance de tais narrativas, a resposta paradoxal é a seguinte: no sacrifício.

O paradoxo já fora notado pela antropologia há muitas décadas e encontra uma clara formulação nas seguintes palavras:

Em todo sacrifício há um ato de abnegação, já que o sacrificante se priva e dá. E geralmente essa abnegação lhe é mesmo imposta como um dever, pois o sacrifício nem sempre é facultativo; os deuses o exigem. [...] Para que o sagrado subsista, é preciso dar-lhe sua parte, e é com a parte dos profanos que se faz essa reserva. ${ }^{38}$
A divindade exige aquilo de que ela própria necessita para se constituir enquanto tal: seja na cultura hebraica, ${ }^{39}$ seja na cultura helênica, ${ }^{40} \mathrm{o}$ sacrifício compõe o próprio ser divino. Ele é responsável pelo estabelecimento de todas as diferenciações impostas por seu poder: no relato bíblico, a divindade que recebe o sacrifício animal (e rejeita a oferta de frutos da terra $)^{41}$ é a mesma que impõe, em primeiro lugar, a submissão dos animais à humanidade, em segundo, a diferenciação entre homens e mulheres e, em terceiro, a necessidade humana de exploração do trabalho e da terra; no relato hesiódico, podemos constatar o mesmo padrão.

Questionando o fundamento que estabelece o sacrifício animal em prol da divindade, revelamos o abuso responsável por instituir uma oposição "natural" entre a humanidade e os outros animais. Afinal, nessas narrativas, o fundamento de tal diferenciação reside numa imposição que - de um modo ou de outro - é estabelecida a partir do próprio poder divino: no relato bíblico, a divindade traz os animais para que o homem lhes dê seus respectivos nomes (Gênesis 2:19); ${ }^{42}$ no relato hesiódico, a divindade institui um rito para se beneficiar, por meio do ser humano, com a oferta de um animal sacrificado - ainda que Prometeu inverta parcialmente as expectativas da divindade, resguardando as partes comestíveis do sacrifício para a humanidade, o papel da vítima animal não é em nada alterado com seu expediente (Teogonia, vv. 535-58; Trabalhos 
e dias, vv. 42-7). O que esses relatos, contudo, deixam na sombra é o fato de que humanidade e animalidade aproximam-se a tal ponto, em certos momentos, que deveríamos admiti-los como irremediavelmente confundidos.

LaCocque chama atenção para isso de maneira exemplar em seu comentário e gostaríamos de retomar seu raciocínio nas próximas linhas. ${ }^{43}$ Em Gênese 3:1, a serpente é descrita como "astuta, mais do que qualquer animal do campo que fez o Eterno Deus”. Ainda que a astúcia apareça em certos momentos do texto bíblico com um valor positivo (como em Provérbios, por exemplo), na narrativa que ora nos ocupa a artimanha e a sutileza são meios de sedução em vista de uma alternativa às relações até então estabelecidas. Em todo caso, a narrativa indica que

a serpente é o animal por excelência, o chefe no reino anima e seu representante. Quando conversa com a serpente, Eva fala com $o$ animal. Da mesma forma, aliás, a mulher representa aqui bem mais do que ela própria; enquanto mãe da humanidade, assim como lado "tenro" do andrógino, ela representa o ser humano. O humano se volta para o animal. ${ }^{44}$

No momento em que o casal edênico come o fruto da árvore proibida, seduzido pela serpente, sua condição human está doravante ligada ao animal de modo irreversível. ${ }^{45} \mathrm{No}$ relato de Hesíodo, Pandora exercerá uma função análoga à da primeira mulher bíblica, posto que o elemento animal a princípio dominado pela humanidade nas duas narrativas - retornará definitivamente e passará a compor de modo incontornável a própria condição humana. Como bem indicado por Nicole Loraux, Pandora é uma criatura mista: tem algo de divino, algo de humano e algo de animal. ${ }^{46}$ Os seguintes versos de Hesíodo são a melhor evidência disso (na tradução de Mantovaneli, alterada):

Assim falou e gargalhou o pai de homens e deuses.

E ordenou ao ínclito Hefesto para que presto

misturasse terra e água e impusesse voz humana [anthrốpou]

e força. E que à face assemelhasse às deusas imortais

belo talhe amável de virgem. Mais tarde a Atena

que lhe ensinasse sua obra: tecer tela poliurdida.

A dourada Afrodite, que espargisse graça à cabeça e despertasse desejo terrível, e preocupações devoradoras de membros.

"Damos-lhe mente canina [kýneòn te nóon] e o caráter fingido.", ordenou a Hermes, mensageiro argifonte.

(Trabalhos e dias, vv. 59-68)

Ora, posto que Pandora seja responsável por introduzir a sexualidade e a reprodução - por meio dessa assimetria entre o mesmo e o outro -, é necessário afirmar que ela se revela, além de portadora da condição humana, a instituidora 
de uma ponte definitiva entre a humanidade e o animal. ${ }^{47}$ Ainda assim, o sacrifício manteve-se nos mesmos moldes estabelecidos anteriormente ao advento da primeira mulher e isso só pode ser compreendido no interior da cadeia de contradições que implicam umas às outras e se fundamentam na imposição daquele mesmo poder por meio da violência.

A lógica dessa imposição verifica-se ainda na ideia de que a primeira mulher, tanto no Gênesis quanto nos poemas de Hesíodo, ocupe uma posição derivada e subalterna com relação à do(s) homem(ns). Não pretendemos retomar as leituras que propõem a precedência masculina - se não hierárquica, pelo menos temporal - com relação ao advento da mulher, ${ }^{48}$ mas sim demonstrar a impropriedade de tal interpretação com base numa análise dos próprios termos empregados nas respectivas passagens. ${ }^{49}$

No trecho bíblico, é dito que "formou o Eterno Deus ao homem [ha'adam], pó da terra [ha'adamah], e soprou em suas narinas o alento da vida" (Gênesis 2:7). A palavra aí traduzida por "homem", embora seja explicada pelo Dictionary of Classical Hebrew como "o primeiro ser humano [the first human being] [...], enquanto primeiro nome em genealogia [as first name in genealogy]", pode "com frequência distinguir-se apenas de modo incerto de "ser humano" em geral [distinction "human being" oft. uncertain]". ${ }^{50} \mathrm{Ou}$ seja, é possível afirmar que nessa passagem um primeiro "ser humano" foi criado, não um primeiro "homem". Em Gênesis 2:22, quando se diz que "fez o Eterno Deus (da) costela que tinha tomado do homem uma mulher, e a trouxe ao homem", o que aí vai traduzido por "homem" é ainda a mesma palavra genérica para "ser humano", enquanto "mulher" é ishah, cujos principais significados dicionarizados são: "usualmente mulher, parceira sexual legítima de um homem e mãe de seus filhos [usu. wife, legitimate sexual partner of a man, and mother of his children]" ou ainda "mulher, sem referência ao estado civil [woman, without ref. to marital status]" ${ }^{51} \mathrm{O}$ fato mais surpreendente, contudo, espera-nos no versículo seguinte: "E disse o homem [ha'adam]: Esta vez é osso dos meus ossos e carne da minha carne; a esta será chamada mulher [ishah], porque do homem [iyshi] foi tomada esta" (Gênesis 2:23). Ora, apesar do que diz o próprio versículo, acerca da derivação da mulher a partir do homem [me'iysh], o fato é que aquele primeiro "humano [ha'adam]", ainda excessivamente cru em sua ligação com o "pó da terra [ha'adamah]", só é de fato definido como "homem [iyshi]"52 - do ponto de vista das palavras e da lógica implícita à própria língua - a partir da mulher [ishah]. Ou seja, se há alguma derivação (como o trecho parece implicar), essa seria a de uma masculinidade que só pode se definir a partir de uma feminidade instaurada no seio da própria humanidade. Ainda assim, o texto parece tentar assegurar - a posteriori uma derivação no sentido contrário. 
Expediente análogo pode ser verificado na narrativa sobre a criação da primeira mulher em cada um dos dois poemas de Hesíodo. ${ }^{53}$ Ainda que haja diferenças no modo como o jogo entre os termos ánthrōpoi [humanos], gynế [mulher] e ándres [homens] opera em cada poema especificamente, a lógica básica é análoga ao que destacamos para o trecho bíblico. Conforme Loraux: "O que se pode ler no texto é o efeito temível da mulher e da palavra gynế: tão logo a mulher é nomeada os ánthrōpoi [humanos] transformam-se em ándres [homens]. ${ }^{\prime 54} \mathrm{~A}$ lógica, tal como presente na Teogonia, é explicada pela mesma autora nos seguintes termos:

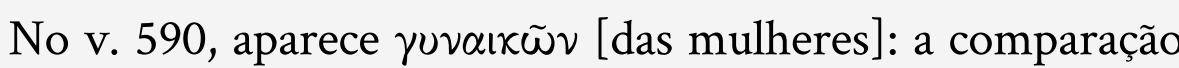
do v. 588 ( $\theta \nu \eta \tau o \dot{c} \varsigma \dot{\alpha} v \theta \rho \omega \dot{\pi}$ ouc [mortais humanos]) e 589

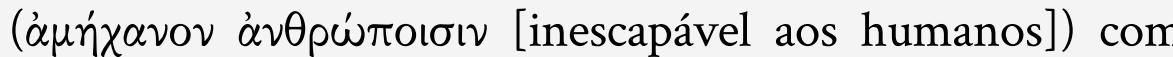
$592(\theta \nu \eta \tau 0 \tilde{\sigma} \sigma \iota \dot{\alpha} \nu \delta \rho \alpha \dot{\sigma} \sigma$ [aos mortais homens]) e 600 ( $(\alpha \nu \delta \rho \varepsilon \sigma \sigma$

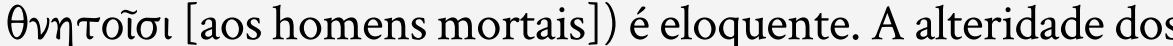

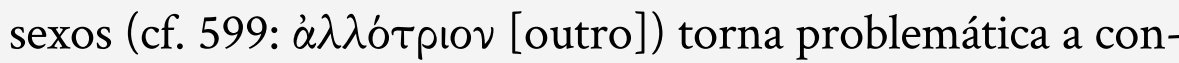
dição de ánthrōpos [humano]. Nos Trabalhos e dias, o jogo com ánthrōpoi [humanos] e ándres [homens] é muito mais complexo, como se Hesíodo marcasse ao mesmo tempo a separação e a implementação da humanidade de hoje. ${ }^{55}$

O jogo de fato é mais complexo nos Trabalhos e dias, mas a lógica é rigorosamente a mesma. Para o período anterior à criação da primeira mulher, os espécimes humanos são sempre referidos pelo termo genérico [ánthropoi], embora o termo específico para "homens [ándres]" seja empregado para se referir àquilo que viria a se constituir no futuro (como no v. 56, "andrásin essoménoisin [aos homens vindouros]", ou na fórmula tradicional do v. 59, "patèr andrôn te theôn te [pai de homens e deuses]"). Quando no v. 80 a palavra gynaîka [mulher] aparece pela primeira vez, recebemos a seguinte informação sobre ela: "Pandora! Pois todos os deuses que habitam olímpias moradas/ deram-lhe dom [dôron edốrēsan], pena aos homens [andrásin] que comem pão" (Trabalhos e dias, vv. 81-2). Ou seja, imediatamente depois da aparição da primeira mulher, temos a informação de que ela era "uma pena aos homens". O mesmo jogo entre ánthrōpoi (antes da primeira gynế) passando a ándres depois dela (e de seus males) é retomado nos vv. 90-2. Em todo caso, também nos poemas hesiódicos, ao contrário do que uma leitura apressada poderia levar a pensar, os "seres humanos [ánthrōpoi]" - ainda pouco diferenciados - só são de fato definidos como "homens [ándres]" - do ponto de vista das palavras e da lógica implícita ao poema - a partir da mulher [gynế]. É como se para definir o "varão" helênico fosse imprescindível que se partisse dos parâmetros oferecidos pela própria mulher. ${ }^{56}$

O desenvolvimento de pares de oposições, instituindo uma diferença primordial que reforça e é reforçada por uma 
série de diferenças derivadas dela, está igualmente presente ao longo de inúmeros trechos dos relatos aqui analisados, como pretendemos paulatinamente indicar. A dependência de um dos polos opositivos com relação ao outro, contudo, solapa toda possibilidade de uma definição autocentrada do mesmo. ${ }^{57}$ Por isso, embora o "homem masculino" só pareça definível a partir de uma "mulher feminina", ambos os relatos esforçam-se por proclamar e garantir - a posterio$r i$ - a precedência do polo masculino. A necessidade dessa imposição posterior encontra sua motivação justamente na impossibilidade de uma definição do que seja $o$ "homem" em si ou $a$ "mulher" em si. ${ }^{58}$

A mesma lógica autoritária de uma divindade impondo seu poder à humanidade - por meio de um sacrifício que resguarda a prevalência humana sobre o animal, bem como a precedência masculina sobre a mulher - está presente no castigo divino que leva à condição humana. Tanto no Gênesis quanto nos poemas de Hesíodo, a condição humana é apresentada como algo que resulta de ações pelas quais a própria humanidade seria culpada, ${ }^{59}$ mas a imposição dessa condição como castigo fundamenta-se ainda no mesmo poder divino e, mais do que isso, reforça todas as imposições anteriormente explicitadas. A submissão animal faz parte desse castigo, ${ }^{60}$ reforçando a naturalidade com que a humanidade arroga-se a prerrogativa de se impor sobre os animais de maneira inquestionada e irrefletida. ${ }^{61}$ Contudo, um resultado ainda mais evidente é a submissão feminina ao homem. Uma vez que o trabalho e o sustento da casa cabem ao homem e a procriação dos filhos é responsabilidade da mulher, os meios de subsistência serão controlados por um grupo, o dos homen ${ }^{62}$ - enquanto apenas a supervivência da raça humana caberá às mulheres. ${ }^{63} \mathrm{Na}$ balança dos poderes, a subsistência apresenta-se como condição mínima para a manutenção de uma posteridade, enquanto o contrário não é de todo verdadeiro: a manutenção de uma posteridade não necessariamente aperfeiçoa os meios de subsistência de homens e mulheres já nascidos (os relatos parecem implicar antes o contrário). ${ }^{64}$ Dessa forma, ainda que o castigo seja apresentado como resposta a uma falta comum a toda a humanidade, suas implicações apenas reforçam as divisões anteriormente impostas de modo arbitrário. Que esse castigo ainda seja caracterizado como um ato de graça concedido pela divindade - em sua manutenção da esperança humana -, mesmo diante da impiedosa atitude da humanidade, é apenas a maneira com que cada narrativa afirma a ausência de sentido em se opor à grandiosidade do poder divino. ${ }^{65}$

Como se vê, uma cadeia de contradições é sugerida por essas narrativas primordiais, a partir da constatação de um poder divino - instituído entre humanos e animais no sacrifício $^{66}$ - até a imposição de diferentes categorias, com suas

EM TESE BELO HORIZONTE $\quad$ v. $22 \quad$ N. 2 MAIO-AGo. 2016 SILVA. Leituras críticas sobre a "condição humana": a partir dos relatos [...]

Crítica Literária, outras Artes e Midias 
respectivas submissões e prerrogativas. Pretendemos ter indicado de que modo essas contradições se constituem e se protegem no sistema de pensamento desenvolvido por tais narrativas, tal como fica claro quando retomamos os pontos principais de nossa argumentação:

* o trabalho e a reprodução são ao mesmo tempo o castigo e a esperança da humanidade - a imposição de sua condição atual (por uma falta cometida contra a divindade) e, ao mesmo tempo, a única possibilidade de se superar a finitude humana

* a mulher é o elemento definidor dos próprios homens responsáveis por subjugá-la; ${ }^{67}$

* o animal é tanto o que aproxima a humanidade da divindade, quanto o que as distancia; ${ }^{68}$

* o sacrifício é uma exigência divina necessária à própria constituição da divindade.

A lógica das narrativas primordiais presentes no início do Gênesis e nos poemas de Hesíodo desdobra-se nesses pontos principais e, embora implique aspectos que poderiam receber atenção especial numa leitura mais detida de cada um deles isoladamente, acreditamos ter apontado os traços que se recobrem em cada uma dessas narrativas, confirmando a existência de uma lógica necessária subjacente a ambas. ${ }^{69}$ Assim justificamos nossa leitura paralela desses relatos judaicos e helênicos, não deixando de evocar sua parcela de importância na constituição de uma corrente de pensamento característica da civilização ocidental. Nossa sugestão é a de que essa mesma lógica subjaza ao estado em que nossa sociedade globalizada se encontra hoje. É certo que sob uma roupagem diversa - adaptada, sem dúvida, aos novos conceitos e sistemas de pensamento desenvolvidos ao longo do tempo -, mas segundo uma necessidade interna que pode se confirmar inteiramente nas narrativas míticas de nossa própria sociedade e cultura. Isso, contudo, ainda ficará para uma leitura por vir... ${ }^{70}$

\section{REFERÊNCIAS}

ADAMS, Carol. A política sexual da carne: a relação entre o carnivorismo e a dominância masculina. São Paulo: Alaúde, 2012.

ASSUNÇÃO, Teodoro Rennó; BRANDÃO, Jacyntho Lins. Semônides de Amorgos e Mimnermo (Fragmentos). In: Ensaios de Literatura e Filologia, Belo Horizonte, v. 4, 1983-1984, p. 209-36.

BENJAMIN, Walter. Sobre a linguagem em geral e sobre a linguagem do homem. Trad. Susana Kampff Lages. In:

Escritos sobre mito e linguagem (1915-21). Org., apres. e notas de Jeanne Marie Gagnebin: trad. Susana Kampff Lages e Ernan Chaves. 2. ed São Paulo: Duas Cidades; Editora 34, 2013. p. $40-73$.

BIBLE. English. Jewish Study Bible. Ed. by Adele Berlin and Marc Zvi Brettler. Jewish Publication Society, Tanakh Translation. Oxford: Oxford University Press, 2004.
EM TESE
BELO HORIZONTE
v. 22
N. 2
MAIO-AG0. 2016
SILVA. Leituras críticas sobre a "condição humana": a partir dos relatos [...] P. 103-124

Crítica Literária, outras Artes e Mídias 
BURKERT, Walter. Die orientalisierende Epoche in der griechischen Religion und Literatur. Heidelberg: Carl Winter; Universitätslag, 1984

CAMPOS, Haroldo de. Éden. São Paulo: Perspectiva, 2004.

CLINES, David (Ed.). Dictionary of Classical Hebrew. Sheffield Sheffield Academic Press, 1993. 6 V.

DERRIDA, Jacques. Éperons: les styles de Nietzsche. Paris Flammarion, 1978.

DERRIDA, Jacques. $\mathbf{O}$ animal que logo sou (A seguir). Trad. Fábio Landa. São Paulo: Editora UNESP, 2002.

ENGELS, Friedrich. A origem da família, da propriedade privada e do estado: trabalho relacionado com as investigações de L. H. Morgan. Rio de Janeiro: Best Bolso, 2014.

FRYE, Northrop. Symbolism in the Bible. In: FRYE, Northrop MACPHERSON, Jay. Biblical and classical myths: the

mythological framework of western culture. Toronto; Buffalo;

London: University of Toronto Press, 2004, p. 3-270.

HESÍODO. Teogonia: a origem dos deuses. Estudo e trad. de Jaa Torrano. São Paulo: lluminuras, 1991 (2. ed., 2012).

HESÍODO. Trabalhos e dias. Trad., estudo e notas Luiz Otávio Mantovaneli. São Paulo: Odysseus Editora, 2011

LACOCQUE, André. Lézardes dans le mur (Genèse 2-3). In: LACOCOUE, André: RICOEUR, Paul. Penser la Bible. Texte d'André LaCocque traduit de l'anglais par Aline Patte et revu par I'auteur. Paris: Éditions du Seuil, 1998, p. 19-56.
LEVIN, Susan. The ancient quarrel between philosophy and poetry revisited: Plato and the Greek literary tradition. Oxford Oxford University Press, 2001.

LORAUX, Nicole. Sur la race des femmes et quelques-unes de ses tribus. In: LORAUX, Nicole. Les enfants d'Athéna: idées athéniennes sur la citoyenneté et la division des sexes. Paris: François Maspero, 1981, p. 75-117.

MANTOVANELI, Luiz Otávio. Mitologar é também filososofar. In: HESÍODO. Trabalhos e dias. Trad., estudo e notas Luiz Otávio Mantovaneli. São Paulo: Odysseus Editora 2011. p. 139-261.

MARQUARDT, Patricia. Hesiod's ambiguous view of woman Classical Philology, v. 77, n. 4, 1982, p. 283-91.

MAUSS, Marcel. Ensaio sobre a dádiva: forma e razão da troca nas sociedades arcaicas. Trad. Paulo Neves. São Paulo: Cosac Naify, 2013.

MAUSS, Marcel; HUBERT, Henri. Sobre o sacrifício. Trad. Paulo Neves. São Paulo: Cosac Naify, 2013

MESCHONNIC, Henri. Poética do traduzir. Trad. Jerusa Pires Ferreira e Suely Fenerich. São Paulo: Perspectiva, 2010.

NIETZSCHE, Friedrich. Além do bem e do mal. Trad., notas e posfácio Paulo César de Souza. São Paulo: Companhia das Letras, 2005

NIETZSCHE, Friedrich. Genealogia da moral. Trad., notas e posfácio Paulo César de Souza. São Paulo: Companhia das Letras, 2009. 
NIETZSCHE, Friedrich. Jenseits von Gut und Böse.

Zur Genealogie der Moral. Kritische Studienausgabe.

Herausgegeben von Giorgio Colli und Mazzino Montinari.

München: de Gruyter, 1999.

NOORDEN, Helen Van. Playing Hesiod: the 'myth of the races' in classical antiquity. Cambridge: Cambridge University Press, 2015.

PENGLASE, Charles. Greek myths and Mesopotamia: Parallels and Influence in the Homeric Hymns and Hesiod. London; New York: Routledge, 1994

RICOEUR, Paul. Mito e história. In:

A hermenêutica bíblica. Apresentação François-Xavier Amherdt. Tradução Paulo Meneses. São Paulo: Edições Loyola, 2006, p. 247-266.

RICOEUR, Paul. Penser la Création. In: LACOCQUE, André; RICOEUR, Paul. Penser la Bible. Texte d'André LaCocque traduit de l'anglais par Aline Patte et revu par l'auteur. Paris: Éditions du Seuil, 1998, p. 57-102.

ROSENBERG, Joel. King and Kin: Political Allegory in the Hebrew Bible. Indiana: Indiana University Press, 1986.

SÉCHAN, Louis. Pandora, I'Ève grecque. Bulletin de l'Association Guillaume Budé, n. 23, 1929, p. 3-36.

TORÁ. Português e hebraico. Torá: a Lei de Moisés. Trad. explicações e comentários do rabino Meir Matzliah Melamed. São Paulo: Editora e Livraria Sêfer, 2001.
VERNANT, Jean-Pierre. À la table des hommes : mythe de fondation du sacrifice chez Hésiode. In: VERNANT, Jean-Pierre. Oeuvres : Religions, Rationalités, Politique. V. 1. Paris : Éditions du Seuil, 2007, p. 891-973.

VERNANT, Jean-Pierre. Le mythe hésiodique des races. Essai d'analyse structurale. In: Revue de l'histoire des religions, Tome 157, n. 1,1960 , p. 21-54

VERNANT, Jean-Pierre $\mathbf{O}$ universo, os deuses, os homens. Trad. Rosa Freire de Aguiar. São Paulo: Companhia das Letras, 2000.

WALCOT, Peter. Hesiod and the Near East. Cardiff: University of Wales Press, 1966.

WEST, Martin L. The East Face of Helicon: West Asiatic Elements in Greek Poetry and Myth. Oxford: Clarendon Press, 1997.

\section{NOTAS}

1. Num de seus estudos do Gênesis, Ricoeur afirma que em narrativas de eventos primordiais pode haver a função arquetípica, responsável por universalizar o que se narra, e a função etiológica, com a qual se explica o presente. E acautela: "Mais ni la fonction universalisante (archetypale) ni la fonction étiologique (causale) n'epuisent sans doute le rôle fondateur des evénements primordiaux [...]. ॥ (RICOEUR. Penser la Création, p. 60)

2. MESCHONNIC. Poética do traduzir, p. XXXIX.

3. Um excelente apanhado da influência determinante da Klassische Philologie e da Altertumswissenchaft, tal como estabelecidas a partir de Wolf e Winckelmann, em fins do séc. XVIII, pode ser encontrado em Burkert (Die orientalisierende Epoche in der griechischen Religion und Literatur, p. 7-12) 
4. BURKERT. Die orientalisierende Epoche in der griechischen Religion und Literatur, p. 117

5. DERRIDA. O animal que logo sou (A seguir), p. 83.

6. Dentre essas diferenças, uma das mais complicadas é a concepção de tempo subjacente a cada uma dessas narrativas primordiais. Julgamos interessante a analogia empregada por Northrop Frye para contrapor uma noção de tempo cíclico a uma noção de tempo linear (ou historico). O primeiro seria mais característico dos poemas hesiódicos (VERNANT. Le mythe hésiodique des races, p. 25), nos quais os mitos de criação são sexuais, enquanto o segundo estaria mais presente nos primeiros relatos do Gênesis (LACOCOUE. Lézardes dans le mur (Genèse 2-3), p. 27), nos quais as narrativas de criação são antes artificiais. Para mais detalhes, cf. FRYE. Symbolism in the Bible, p. 139-40.

7. RICOEUR. Mito e história, p. 248.

8. RICOEUR. Mito e história, p. 263.

9. É interessante levar em conta o que afirma Ricoeur (Penser la Création, p. 61): «Créer, c'est former, donner figure et consistance. Il en sera de même de la relation que Genèse 1 fait de la création du monde : I'abîme est là, les ténèbres aussi, ainsi que les eaux primordiales ; la parole ne crée pas de rien, et les séparations successives qui rythment les six jours de l'oeuvre constituent l'acte createur lui-même. La notion de Création ex nihilo répondra à érieure et concernera ce que Leibniz appellera, I'origine radicale des choses. "

10. CAMPOS. Éden, p. 28.

11. Segundo LaCocque (Lézardes dans le mur (Genèse 2-3), p. 29): "Le mythe de Genèse 1 a pour but de faire revenir le narratif "Lu rituel, en parallèle avec l'ancien Enuma elish mésontratif par exemple." - E ele explica que Gênesis 1 deve ter sido pacrito quando YHWH e suas promessas à nacão parecio desacreditadas. Northrop Frye (Symbolism in the Bible p. 133) menciona que a ênfase dada aos sete dias no "primeiro r. 133) Criação
Ricoeur (Penser la Création, p. 92) o confirma: « [...] la création sans résistance, illustrée par Genèse 1, prend sens dans un cadre essentiellement liturgique, comme l'atteste la référence au sabbat, qui paraît bien être le pôle organisateur de ce récit inaugural. „

12. Lê-se numa nota ao respectivo versículo, em Jewish Study Bible: "Whereas the next account of human origins (Gen. 2.4b24) speaks of God's creation of one male from whom one female subsequently emerges, Gen. ch 1 seems to speak of groups of men int women creat sinultaneously. The division of humankind int , p. 14).

13. Com relação aos dois mitos hesiódicos, Vernant alerta-nos para o seguinte: « Les deux mythes sont liés. Ils évoquent l'un et l'autre un ancien temps où les hommes vivaient à l'abri des souffrances, des maladies et de la mort ; chacun rend compte, à sa façon, des maux qui sont devenus, par la suite, inséparables de la condition humaine. » (VERNANT. Le mythe hésiodique des races, p. 21)

14. Para detalhes sobre a constituição desse tópos poético e filosófico, cf. o livro de Helen van Noorden (2015), Playing Hesiod: The 'Myth of the Races' in Classical Antiquity.

15. MANTOVANELI. Mitologar é também filosofar, p. 202.

16. West (The East Face of Helicon, p. 312-8) explicita os paralelos desse mito hesiódico com outras passagens bíblicas e certos textos orientais.

17. No "mito das idades" não há uma menção explícita à especificação dos gêneros (como no caso do "primeiro relato" bíblico), mas é o que se pode inferir ex silentio. Além disso, na raça de prata (a segunda das cinco), diz-se que os filhos ficavam por cem anos "ao lado da digna mãe [parà mêtéri kednêi]" (Trabalhos e dias, v. 130).

18. No caso do "mito das idades", isso é válido para os homens da idade de ouro, para quem "todos os bens se dispunham, [pois] a terra farta dava fruto espontânea, muito e sempre [esthlà dè pánta/ (116-7) - O mesmo e infere do que está dito na Toŕ e "E para 
todo animal da terra e toda ave dos céus, e tudo o que se arrasta sobre a terra, em que haja alma viva; e toda verdura de erva (será) para comer." (Gênesis 1:30) - Numa nota de Jewish Study Bible ao mesmo versículo: "Humankind, animals, and birds all seem originally to be neither vegetarians nor carnivores, but frugivores, eating the seeds of plants and trees." (BIBLE, p. 14).

19. Para uma análise estrutural, hoje clássica, dessa complexidade, cf. VERNANT. Le mythe hésiodique des races, p. 21-54. Para outros 224; NOORDEN. Playing Hesiod, p. 1-88.

20. Conforme Ricoeur (Penser la Création, p. 63): « [...] la narration n'est pas la seule manière de se reporter au temps primordial. Genèse 1 n'est pas un récit, mais un poème didactique ; ce n'est qu'en un sens impropre, en raison de la succession des paroles et des actes de division, que l'on peut dire que Genèse 1 " raconte" la création du monde ; il manque à ce quasi-récit le caractère dramatique des événements rapportés en Genèse 2, qui relèvent ainsi du récit au sens fort. "

21. Para uma exegese limitada a esse relato bíblico (e em suas relaçōes.

22. Para uma análise concentrada nas versões hesiódicas do mito de Prometeu, cf. VERNANT. À la table des hommes, p. 891-973. O autor sugere a lógica da relação entre o sacrifício sangrento, o fogo prometeico e a criação da mulher.

23. A sugestão dessa "divisão" foi proposta por Ricoeur (Pense la Création, p. 68): "C'est le « pour soi » de la séparation qui advient avec la création de l'humanité racontee en Genèse 2,4b"successivement" deux histoires qui présentent chacune une certaine unité narrative, mais qui empiètent l'une sur l'autre. "

24. RICOEUR. Penser la Création, p. 72.

25. Para além de diferenças pontuais, é preciso lembrar o seguinte: "[...] there is another difference between the versions of the
Pandora story in the Theogony and the Works and Days: they serve a very different purpose. In the Works and Days the history of Prometheus and Pandora explains why we should have to toil to support life in a world controlled by a supposedly benevolent Zeus. [...] The Theogony, on the other hand, describes the creation, and its story of Prometheus, therefore, culminates in the creation of the first woman." (WALCOT. Hesiod and the Near East, p. 62)

26. Para mais detalhes da região, cf. VERNANT. À la table des hommes, p. 921-2.

27. O propósito etiológico de uma narrativa explicando as razões por que a humanidade oferta a pior parte do sacrifício aos deuses foi comentado inúmeras vezes. Em todo caso, vale a pena recordar o comentário ao incidente bíblico do sacrifício de Isaac por Abraão (Gênesis 22:1-18), tal como proposto por Frye (Symbolism in the Bible, p. 66): "We can see at work here the principle that offering to God as a sacrifice what you most want yourself gets to be inconvenient after a while, so various substitutions are made. In fact, it is one of the motifs in Greek mythology associated with Prometheus. Prometheus' real sin was in persuading men that the gods didn't want any of the real meat when they offered a sacrifice they'd be quite content with the entrails and the offal. And they were not. And so, every so often there comes the feeling that the deity wants the full payment and without cheating." - Para uma crítica do reducionismo dessas leituras, na medida em que tais mitos lidam com muito mais do que explicaçoes e justificativas daquilo que se oferecia aos deuses no sacrifício, cf. VERNANT. À la table des hommes, p. 891-2.

28. Walcot (Hesiod and the Near East, p. 60) nota o paralelismo entre o estratagema de Prometeu, para enganar Zeus, e o de Zeus, Prometeus' collection of bones dressed up in fat spell out the same moral lesson, the folly of basing a judgment on external appearance by itself, for beauty is always likely to be no more than skin deep, and something may look attractive but be deadly. Epimetheus and Zeus fall victim to an identical trick, and Zeus, therefore, pays his enemies back in their own coin by an act of

EM TESE BELO HORIZONTE $\quad$ v. $22 \quad$ N. 2 MAIO-AGo. 2016 SILVA. Leituras críticas sobre a "condição humana": a partir dos relatos [...] P. 103-124

Crítica Literária, outras Artes e Mídias 
deceit which is comparable but much more crushing." - Já Vernant (A la table des hommes, p. 944) atenta para outro paralelo possível: "Dans les deux versions aussi, avec une commune insistance, le texte précise que cette création d'un être, inexistant jusquelà, constitue la réplique au vol de Prométhée. La femme, ce mal, kakon, est introduite dans le monde anti puros, en contrepartie du feu (Theógonie, 570 ; Travaux, 57).

29. West (The East Face of Helicon, p. 310-1) chama atenção para o seguinte: "More generally, the motif that several different deities combine to bestow different qualities upon a person is well attested in to tópos por Hesíodo, do tópos por Hesíodo, empregando-o na descriçào da concepçă dessa primeira mulher como um belo mal [kalón kakón], pode conter alguma ironia intertextual para com as tradiçoes orientais. Para una análise da dubiedade inerente ao dom no pensamento

de várias sociedades antigas, cf. MAUSS. Ensaio sobre a dádiva.

SECHAN. Pandora, I'Ėve grecque, p. 12-7; WALCOT, Hesiod and the Near East, p. 61; MAROUARDT. Hesiod's ambiguous view of woman, p. 289-90; PENGLASE, Greek myths and Mesopotamia, p. 178; VERNANT. A la table des hommes, p. 959-73.

31. Embora seja preciso notar que não existe uma antropogonia propriamente dita em Hesiodo, como muitos comentadores já East, p. 57; VERNANT À la tabl. WA hommes, p. 925-31. es, p. 925-31.

32. A nomeação dessa primeira mulher é dotada de uma dimensão etimológica em ambos os relatos. Eva [Chawwah] recebe um nome que significa também "doadora de vida" (ROSENBERG. Kind and Kin, p. 61), em Gênesis 3:20: "E chamou o homem o nome de sua mulher, Eva, porque ela era a mãe de todo vivente." - Com relação a Pandora, Hesíodo sugere que seu nome indique o fato de ter recebido presentes [dốra] de todos os deuses (Trabalhos e dias , vv. 81-2).

33. O título de um artigo já datado de Sechan (1929) o indica bem: "Pandora, I'Ėve grecque ". Algo no mesmo sentido é indicado pelo comentário de West (The East Side of Helicon, p. 120-1): “The Yahwist writer of Genesis 3 puts the change before the Flood, at the time of Adam's disgrace. Adam had had some gardening to do in Eden $(2,15)$, but nothing heavy. But because he took what he should not have taken, what belonged to God, God was angry with him and laid a curse on the soil that had been so free with its gifts (3.17-19). [...] This is closer to the Greek myth as we have it in Hesiod than to Atrahasis. Hesiod, like the Yahwist, holds that originally the fruits of the earth grew in plenty of their own accord and could be garnered with minimal effort. But Zeus 'hid' them out of anger at having been tricked by Prometheus in the matter of the division of sacrificial meat. The effect of Prometheus' trick was that mankind got the best meat, the portion that properly belonged to the gods. That is why we have been condemned to till the earth so laboriously." - Marquardt (Hesiod's ambiguous view of woman, p. 286, n. 6) escreve o seguinte: "That Hesiod is keeping with the tradition that holds a woman responsible for man's misery (e.g Genesis 2.4-25 and 3.1-22) is undeniable."

34. O trabalho aparece como a punição imposta aos homens (Gênesis 3:17-19; Trabalhos e dias, vv. 42-50) por uma ação de desrespeito à divindade: Eva e Adão infringem a proibição de comer o fruto da arvore do conhecimento do bem e do mal (Gênesis 3:1-6), Prometeu tenta trapacear o espírito de Zeus na divisão das partes do sacrifício e no roubo do fogo em benefício humano (Teogonia vv. 535-69; Trabalhos e dias, vv. 46-52). Parte da mesma punição inclui a necessidade da procriação feminina para a manutenção da vida humana - procriação que é representada como um mal inevitável (Gênesis 3:16; Teogonia. vv. 603-12).

35. Tal submissão, no "segundo relato" bíblico, evidencia-se quando o Eterno Deus traz até o homem "todo animal do campo e toda
ave dos céus [...] para ver como os chamaria" (Gênesis 2:1920). Essa noção de uma natureza subserviente à humanidade já estava prevista, de modo ainda mais evidente, no "primeiro relato" (Gênesis 1:28). Tal arranjo é bem destacado por Rosenberg (King and Kin, p. 54). No caso do mito de Prometeu, a hierarquização entre deuses, homens e animais está implícita ao próprio arranjo
EM TESE
BELO HORIZONTE
v. 22
N. 2
MA10-AGO. 2016
SILVA. Leituras críticas sobre a "condição humana": a partir dos relatos [... ] P. 103-124

Crítica Literária, outras Artes e Mídias 
inicial do sacrifício: aos deuses caberia receber a dádiva; aos homens, a necessidade de ofertá-lo; aos animais, serem ofertados. Cf. também VERNANT. À la table des hommes, p. 900. Essa passividade da função reservada aos animais parece ter relação com a perspectiva humana acerca dos mesmos, antes como objetos do que como sujeitos (não custa lembrar que o substantivo "zôión [animal]" é neutro em grego antigo).

36. Em inúmeras passagens de sua obra, Nietzsche analisa corretamente a cadeia de relações aqui apontada, a partir de sua fundamentaça con ma noçáo de poder (entendido como Macht), ta como no 259 de Alem do bem e do mal. Náo podemos, contudo, concordar con seu posicioname co mavoráné à consequencias dessa imposição d própria vida.

37. Ricoeur (Penser la Création, p. 83), falando sobre o relato do Gênesis, afirma algo que é válido para o que apontamos aqui: « [... plus gravement, la parole d'une origine sans témoins ne s'autorise que d'elle-même. Elle se pose en posant le commencement qui la pose. Cette autoréférentialité marque son caractère kérygmatique indépassable. C'est ainsi que le dire de l'origine exerce sa fonction inauguratrice, inaugurale, fondatrice. n - Essa carência de lastro em narrativas fundacionais parece impulsionar o emprego de jogos etimológicos por elas como recurso linguístico para explicar o que está além da possibilidade de explicação. Para detalhes desse procedimento em Hesíodo e sua crítica no Crátilo, de Platão cf. LEVIN. The ancient quarrel between philosophy and poetry revisited, p. $42-79$.

38. MAUSS; HUBERT. Sobre o sacrifício, p. 107-8.

39. Falando dos sacrifícios por incineração, Mauss e Hubert (Sobre o sacrificio, p. 44) mencionam que as gorduras e visceras eram queimadas pelos hebreus no fogo do altar para chegar ao deus (Levítico 3:3-5; 7:22-27; 9:19-21), em forma de fumaça agradável para a divindade (Levítico 1:9; 1:13; 1:17; 2:2; 2:9; Salmos 66:15). O primeiro sacrifício animal na Bíblia se dá pouco após a a importância do rito sacrificial para a divindade só é ressaltada no que se diz sobre Noé, em Gênesis 8:20, após o fim do dilúvio: “E construiu Noé um altar ao Eterno, e tomou de todo quadrúpede puro e de toda ave pura, e ofereceu ofertas de elevação no altar. E sentiu o Eterno o cheiro de suavidade; e disse o Eterno para Si: 'Não tornarei a maldizer mais a terra por causa do homem; que o impulso do coração do homem é mau desde sua mocidade; e não tornarei mais a ferir todo (ser) vivo como fiz. [....."' - A mesma concepção subjaz aos relatos sumério-assírio-babilônicos, cf. PENGLASE. Greek myths and Mesopotamia, p. 186-7.

40. Além de aparecer no momento em que deuses e homens distinguiam-se em Mecona (Teogonia, vv. 535-6), o sacrifício é ta importante que quando Hesiodo justifica a condenação da raça de prata, no mito das raças, ele afirma o seguinte: "[... Nem cultuar imortais tampouco quiseram,/ nem fazer sacrificio hom altares sagrados dos bem-aventurados./ É norma entre os homens, segundo o costume. Entá/Zeus Cronida, encolerizado, os escondeu, pois honra/ não deram aos deuses bem aventurados que moram no Olimpo/ e ainda, depois, tambem essa raça oculto debaixo da terra." (Trabalhos e dias, vv. 135-40) - Além disso, na Odisseia (III, 51; VII, 201), narra-se como os deuses aparecem participando de banquetes sacrificiais com os humanos. No Hino Homérico a Deméter, afirma-se que "os que têm palácio no Olimpo recebem honra muito gloriosa dos privilégios e dos sacrifícios [geráōn t'erikydéa timèn kaì thysiôn]" (h.Hom. 2, v. 311-2). E Heródoto (IV, 62) menciona a relação entre oferendas por incineração, fumaça cheirosa e sua recepção pelos deuses (especificamente entre os povos citas, embora seus comentários sejam mais reveladores da cultura helênica do que de qualquer outra).

41. Na história de Caim e Abel, em Gênesis 4:1-16. Para uma interpretação da passagem, cf. FRYE. Symbolism in the Bible, p. 61. - É curioso que nesse momento a humanidade ainda não estivesse autorizada a consumir carne animal uma vez que tal permissão só é explicitamente concedida a Noé (Gênesis 9:3). 
42. A noção de que o homem impõe-se aos animais - e à natureza de modo geral - por meio de sua nomeação está presente ao longo de um ensaio de Benjamin, como quando afirma: "Nessa segunda história da Criação, a criação do homem não se dá pela palavra (Deus disse - e assim se fez), mas a esse homem que não foi criado a partir da palavra é conferido agora o dom da língua, que o eleva acima da natureza." (BENJAMIN. Sobre a linguagem em geral e sobre a linguagem do homem, p. 60) - Algumas de suas considerações são retomadas por Derrida ( $O$ animal que logo sou (A seguir), p. 40-4).

43. LACOCQUE. Lézardes dans le mur (Genèse 2-3), p. 31.

44. Em tradução. No original: « [...] le serpent est l'animal par excellence, le chef dans le royaume animal et son représentant. Lorsqu'elle parle avec le serpent, Ėve parle avec l'animal. De même, d'ailleurs, la femme représent ici bien plus qu'elle-même en tant que mère de l'humanité, ainsi que le côté « tendre " de l'androgyne, elle représente l'être humain. L'humain se tourne vers I'animal. „ (LACOCOUE. Lézards dans le mur (Genèse 2-3), p. 31-2)

45. Nessa mesma passagem, LaCocque chama atenção para o jogo existente entre a nudez da humanidade (quando eles são chamados "nus [orumim]") e a "astúcia" da serpente (substantivo que, em hebraico, ecoa a palavra anterior (orum]). $O$ autor atenta anda para outros aspectos dessa relaço en a humandade e a 2-3), p. 32).

46. LORAUX. Sur la race des femmes et quelques-unes de ses tribus, tradição helênica, cf. VERNANT. À la table des hommes, p. 949-50.

47. Essa relação entre a humanidade (sobretudo na figura da mulher) e a animalidade é ainda mais evidente num poema de Semônides de Amorgos (o fr. 8 da edição de Adrados, fr. 7 de West), um poeta pouco posterior a Hesiodo. Para uma traduça desse poenta BRANDÃO. Semonides de Amorgos E Mimn, c. As (FuNÇÄO; p. 216-223. - Para uma análise do poema, cf. LORAUX. Sur la race des femmes et quelques-unes de ses tribus, p. 95-117.

48. Contemporaneamente, as interpretações hebraicas da passagem bíblica mostram-se mais sensíveis ao problema do que aquelas oferecidas por helenistas à passagem hesiódica. Isso provavelmente ocorre devido à necessidade de se atualizar ao conto escrita há mais de dois milênios. Nesse sentido, vejamos o 24: “The LORD's cretion of Jewish Struy Bible a Genesis 2:1824: "The LORD's creation of woman from man emphasizes the close connection between them and lays the groundwork for the in $v$. 24. The creation of the (and its association with procreation) in v. 24. The creation of the woman after the man and from a part of his body need not imply the subordination of women to men. - Em sentido parecido, o comentánio ao mesmo trecho da Torá (2001). Entre os helenistas, e comum a afirmaçáo de que o homem precedeu a mulher: " les hommes existaient déjà depuis un certain temps lorsque leur vint la première femme, par suite d'un inciden aussi lamentable que fortuit. " (SECHAN. Pandora, I'Eve grecque, p. 8) - Cf. WALCOT. Hesiod and the Near East, p. 62; PENGLASE. Greek myths and Mesopotamia, p. 170; VERNANT. O universo, os deuses, os homens, p. 71

49. A importância da dimensão linguística na exegese desse relato do Gênesis foi destacada por Rosenberg (King and Kin, p. 57-9).

50. CLINES. Dictionary of Classical Hebrew, p. 129

51. CLINES. Dictionary of Classical Hebrew, p. 404.

52. Assim é a definição dicionarizada de iyshi: "homem [man]", "cada um, distributivamente [distributively, each, of individuals]", "um, algum [one, someone]", "homem, marido [man, husband]", "homem armado, guerreiro [armed man, warrior] ", chegando até [human being]" e "animal macho [male animal]" (CLINES. Dictionary of Classical Hebrew, p. 222) - A frequência com que o termo aparece no sentido mais especificamente masculino autoriza-nos a manter nossa leitura da passagem.
EM TESE
BELO HORIZONTE
v. 22
N. 2
MAIO-AGO. 2016
SILVA. Leituras críticas sobre a "condição humana": a partir dos relatos [...] P. 103-124

Crítica Literária, outras Artes e Mídias 
53. Vernant (À la table des hommes, p. 921; p. 943-4) já chamava atenção ao fato, embora não ousasse tirar as consequências inevitáveis daquilo que constatava.

54. Tradução nossa. No original: "Ce que, par contre, on peut lire dans le texte, cest l'effet redoutable de la femme et du mo ge transforment en andres. (LORAUX. Sur la race des femmoi quelques-unes de ses tribus, p. 81)

55. Tradução nossa. No original: « En 590 apparaît le mot yuvaıkw̃v :

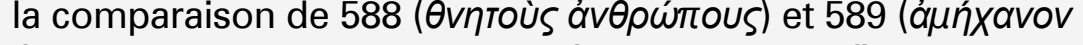

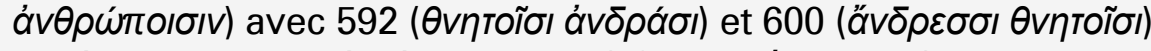
est éloquente. L'altérité des sexes (cf. 599 : ádhótpıov) rend problématique la condition d'anthrôpos. Dans les Travaux, le jeu sur anthrôpoi et andres est beaucoup plus complexe, comme si Hésiode marquait à la fois la séparation et la mise en place de I'humanité d'aujourd'hui. » (LORAUX. Sur la race des femmes et quelques-unes de ses tribus, p. 81, n. 28)

56. Aproveitamos a oportunidade para esboçar nossa discordância num ponto específico, da excelente análise de Nicole Loraux A buto aual nessas passica ens uma equiporãa ta entre ánthrōpos em detrissan uñ em detrimento da gyne (C.. LORAUX. Sur la race des femmes et quelques-unes de ses tribus, p. 92-3. « [.... les mâles accaparent le statut d hommes à leur propre usage ? Peut-être. 川). Porém, a leitura de vátios trechos dos Trabalhos e dias simplesmente náo faria sentido se entendêssemos que a palavia ánthropoi, após o surgimento da primeira gyné, nâo incluisse ao mesmo tempo homens e mulheres, ou seja, a humanidade inteira. Ess divergência de leitura se deve a duas razoes principais: i) a estudiosa concentra propositalmente suas análises de maneira quase exclusiva na Teogonia (LORAUX. Sur la race des femmes et quelques-unes de ses tribus, p. 79); ii) ela pretende radicalizar a brecha que separa a mulver do homem no discurso masculino em textos da Antiguidade (LORAUX. Sur la race des femmes et quelques-unes de ses tribus, p. 80). Nossa estratégia, ao contrário da dela, é ler minuciosamente o discurso masculino da Antiguidade e, apontando as contradições inerentes ao mesmo, demonstrar sua impossibilidade de sustentação: partir de suas premissas, revelar suas contradições internas e, fazendo com que ele se volte contra si mesmo, sugerir uma via para além de suas aporias aparentes.

57. Em sua análise da "verdade" como "mulher" na obra de Nietzsche, Derrida explica tais questões nos seguintes termos: «Dès qu'on determine la difference sexuelle en opposition, chaque terme renverse son inage dans laúre. Proposition dont les deux $x$ maint à la fois sujets et predicars, la copú un miroir. Telle est la machine de la contadiction, (DERRDA. Eperons, p. 75, n. 1

58. Na mesma obra de Derrida citada na nota anterior, o autor afirma o seguinte (ainda a partir da obra de Nietzsche): « II n'y a donc pas de vérité en soi de la différence sexuelle en soi, de l'homme ou de la femme en soi, toute l'ontologie au contraire présuppose recèle cette indécidabilité dont elle est l'effet d'arraisonnement, d'appropriation, d'identification, de vérification d'identité. " (DERRIDA. Éperons, p. 84)

59. Na narrativa do Gênesis, a culpa humana é evidente. Já no mito de Prometeu, poderia ser defendido que a culpa imediata é do tita. Contudo, a humanidade é a út qua beneficiária de seus atos e, desse modo, alguma parcela da culpa tambem recairia 59) afirma Nesse sentido, Walcot (Hesiod and the Near East, $p$. 59) afina o seguinte: "f Zeus here is a cruel god, it is the Tip. and mankind who are to blame, they insulted the majesty of Zeus, and by such a standard Zeus would be less than a great god if he failed to retaliate. Mankind is as guilty as Prometheus, for we remember that, according to the Works and Days, one evil man can blight a whole city (verses 240-1). - A equivalência estrutural da posição de Prometeu no arranjo mítico e comparada à da própria humanidade tambem por Vernant (A la table des hommes, p. 901-2).
EM TESE
BELO HORIZONTE
v. 22
N. 2
MA10-AGO. 2016
SILVA. Leituras críticas sobre a "condição humana": a partir dos relatos [...] $\quad$ P. 103-124

Crítica Literária, outras Artes e Mídias 
60. Na sequência de ambas as narrativas, a humanidade se alimentará do animal e isso e, sem dúvida, a maior barreira imposta entre eles (LACOCOUE. Lézardes dans le mur (Genèse 2-3), p. 32). Ademais, no texto bíblico, a serpente é responsabilizada pela "queda" da humanidade e, por isso, amaldiçoada pelo Eterno Deus com uma condição mutilada, infértil e conflituosa (Gênesis 3:14). Para mais detalhes dessa leitura, cf. LACOCOUE. Lézardes dans le mur (Genèse 2-3), p. 36. Além disso, quando expulsa o casal do Éden, o Eterno Deus faz "túnicas de pele" para vesti-los (Gênesis 3:24) - a implicação clara é a de que a existência do animal se mantém a serviço da humanidade (ROSENBERG. King and Kin, p. 54-5). No mito de Prometeu, é afirmado que a primeira mulher traz uma coroa de ouro ao redor da cabeça, com muitos lavores gravados por Hefesto, prodígio aos olhos: "das feras que a terra e o mar nutrem muitas [knốdal' hós' ếpeiros pollà tréphei ēdè thálassa]/ ele pôs muitas ali (esplendia muita a graça)/ prodigiosas iguais às que vivas têm voz [zốoisin eoikóta phōnéessin]." (Teogonia, vv. 578-84) - A menção a uma coroa com tais entalhes sugere uma prevalência humana sobre os animais, a ponto de se falar de um possível pape dessa primeira mulher como "senhora das feras [pótnia thērôn]" (MARQUARDT. Hesiod's ambiguous view of woman, p. 287). Para uma outra visão e apresentação de certa bibliografia, cf. LORAUX. Sur la race des femmes et quelques-unes de ses tribus, p. 89.

61. Nietzsche, no $\$ 291$ de Além do bem e do mal, mostra-se atento aos mecanismos de imposição humana sobre os animais, servindo-se de sua "boa consciência [gute Gewissen]": “O homem, um animal complexo, mendaz, artificial, intransparente, e para os outros animais inquietante, menos pela força que pela astúcia e inteligência, inventou a boa consciência para chegar a fruir sua alma como algo simples; e toda a moral e uma decidida e prolongada falsificaçao, em virtude da qual se torna possível a fruição do espetáculo da alma." (NIETZSCHE. Além do bem e do mal, p. 176).

62. Ao contrário do que o prefácio de Engels (A origem da família, da propriedade privada e do estado, p.8-9) pareceria sugerir, o autor indica com acerto o papel do monopólio masculino dos meios de produção, no contexto de desenvolvimento da agropecuária em certas sociedades antigas, para o processo histórico de submissão da mulher (ENGELS. A origem da família, da propriedade privada e do estado, p. 65-70). Aristóteles (Pol. 1263a9-17) também já problematizara, de forma incidental, a questão da posse do produto do trabalho agropecuário em sua relação com a predominância masculina.

63. Nietzsche relaciona de maneira sucinta, mas correta, a sujeição da mulher com a questão da procriação (na sessão 8 da $3^{\mathrm{a}}$. dissertação da Genealogia da moral, p. 92). Além disso, aponta a meios para o movimento de "superação" dess sumo (enta no com (s 239): “Em to pou tom ironico), em Além do bem e do mal (s 230): "Em toda parte onde o espinto industral venceu o espinto militar e aristocrático, a mulher aspira à independência econômica e legal de um caixeiro (nach der wirthschattlichen und rechtlichen Selbstandigkeit eines Commis]: "a mulher como caixeira" - está escrito no portal da sociedade moderna que se forma. Apoderando-se de tal maneira de novos direitos, buscando tornar-se "senhor" e inscrevendo o "progresso" feminino em suas bandeiras e bandeirolas, ela vê realizar-se o contrário, com terrivel nitidez. a mulher está em regressäo." (NIEZSCHE. Alén do bem e do mal, p. 129-30)

64. Como Rosenberg (King and Kin, p. 61) explicita bem para o caso do Gênesis e Loraux (Sur la race des femmes et quelques-unes de ses tribus, p. 89-90) para os poemas de Hesíodo.

65. A "graça" do castigo divino foi bem notada por alguns comentadores. Sobre o texto bíblico, LaCocque (Lézardes dans le mur (Genèse 2-3), p. 23) afirma: "Ainsi que le montre le cours de Thistoire, î suffit quadam désobéisse au commandement pour que le monde soit replongé dans le chaos dont il avait initialement émergé. Et pourtant, la mort et l'aneantissement ne triomphent pas - malgré l'avertissement divin : môt tamut " tu mourras aussitôt " Genèse 2,17). On me peut qu'y voir la grâce de Dieu. " - Para os poemas hesiódicos, Mantovaneli (Mitologar é também filosofar,

EM TESE BELO HORIZONTE $\quad$ v. $22 \quad$ N. 2 MAI0-AGo. $2016 \quad$ SILVA. Leituras críticas sobre a "condição humana": a partir dos relatos [...] $\quad$ P. 103-124

Crítica Literária, outras Artes e Mídias 
p. 198) nota o seguinte: “[...] a Esperança deve ser interpretada como uma possibilidade de vida concedida aos homens, como uma graça subordinada à aceitação da nova lei moral e política do mundo, que determina o trabalho e a justa repartição dos frutos

Esse papel central do sacrifício na compreensão do mito de

. Esse papel central do sacrifício na compreensão do mito de
Prometeu foi indicado por Vernant (À la table des hommes, p. 896)

67. As narrativas da criação da humanidade, tanto no Gênesis quanto no mito de Prometeu, encerram-se com a certificação de que é preciso submeter a mulher para que a supervivencia da raça humana seja possível. O Eterno Deus diz o seguinte à primeira mulher: "[...] para teu marido será o teu desejo e ele dominará em ti." (Gênesis 3:16) - A argumentação de LaCocque (Lézardes dans le mur (Genèse 2-3), p. 51), segundo a qual tal passagem não conteria qualquer ideia de submissão feminina, é duvidosa e parece oferecer uma exegese que adapta a mensagem religiosa ao contexto contemporâneo. A mesma impressão se dá na interpretação proposta pelos comentários hebraicos da Torá e de Jewish Study Bible. Já em Hesíodo, a necessidade de que a mulher seja vigiada está implicada no episódio em que Pandora abre o pithos [jarro] contendo todos os males (Trabalhos e dias, vv. 94-104), bem como na sugestão de que a raça funesta e as tribos das mulheres, além de amontoarem no ventre o esforço alheio (como os zangões fazem com o fruto do trabalho das abelhas) são parelhas de obras ásperas (Teogonia, vv. 591-602). Ademais, ditos gnômicos precavendo os homens contra as mulheres estão presentes ao longo dos dois poemas e reforçam o que já está sugerido nessas narrativas etiológicas.

68. Reforcemos que essa contradição já fora identificada pela antropologia, pelo menos desde os trabalhos de Mauss e Hubert do início do séc. XX. Na conclusão de seu estudo sobre

sacrifício, afirmavam: "Essa ambiguidade e inerente ao sacrifício. Com efeito, ela se deve à presença do intermediário, e sabemos que sem intermediário não há sacrifício. Por ser distinta do sacrificante e do deus, a vítima os separa ao mesmo tempo que os une; eles se aproximam sem se entregar inteiramente um ao outro." (MAUSS; HUBERT. Sobre o sacrificio, p. 108) - A mesma contradição é retomada por Vernant (Á la table des hommes, p. 897).

69. Em sua análise concentrada nas versões de Hesíodo do mito prometeico, Vernant (À la table des hommes, p. 957) afirmava o seguinte: «Sacifice, agriculture, mariage - tels sont les trois aspects solidaires de la condition humaine depuis que les devenus tout à la fois des andres, des hommes mâles, sont devenus tout à la fois des andres, des hommes mâles, et de pauna munco uma mudaçán nos voúbulos empregados para falar dos tres aspectos solidários da condçác humana implicados pelo mito de

70. Após a conclusão de nossa leitura, certificamo-nos de que muitos de nossos apontamentos continuam válidos para nossa sociedade contemporânea. Nesse sentido, indicamos o estudo de Carol Adams, no qual são sugeridas as relações entre carnivorismo, dominância masculina e exploração - partindo de análises específicas para a sociedade americana, embora tal padrão abranja outras sociedades e culturas (ADAMS. A política sexual da carne). 